\title{
A COMPARATIVE STUDY OF DIRECT MATCHING TECHNIQUES IN BLOOD TRANSFUSION
}

\author{
BY \\ O. G. DODGE \\ From the Blood Transfusion Centre, Sheffield \\ (RECEIVED FOR PUBLICATION NOVEMBER 10, 1951)
}

The discovery of several new blood-group systems within recent years and the development of new techniques for the detection of antibodies have shown that the time-honoured methods for the direct matching of blood preparatory to transfusion are inadequate and may be dangerously fallacious.

Tests in an albumin medium and the use of the indirect Coombs test are the most reliable methods so far developed for detecting incompatibility, and where direct matching which is not urgent is performed in hospital laboratories these procedures should, ideally, always be carried out. (It is, however, realized that this is not yet the case.) Ultimately, perhaps, all direct matching of blood will be carried out by pathologists, blood transfusion officers, and trained technicians working in laboratories equipped for the purpose. At present, however, a great deal of urgent direct matching, especially at night, falls to the lot of harassed and relatively inexperienced junior doctors who have neither the time nor the inclination to pursue the niceties of serological technique. Tube tests in albumin cannot satisfactorily be carried out in less than one and a half hours; the indirect Coombs test requires practice and careful controlling to give valid results, and is, essentially, a laboratory test. Neither of these tests, however reliable their results, is therefore wholly satisfactory as a method for use in emergencies or for those who are not experienced in their use.

The purpose of this paper is to attempt (1) to show the fallacy of compatibility tests in a saline medium ; (2) to demonstrate the reliability of the tube technique of direct matching using an albumin medium ; and (3) to explore certain other methods of direct matching, in an endeavour to find a method which will combine speed and simplicity with the greatest possible degree of reliability.

\section{Scope of the Investigation}

It was decided to test a number of sera against cells of known $\mathrm{ABO}$ group and Rhesus type. The nature of the sera was not known to the investigator; some contained anti-D in complete or incomplete forms (of varying titre) and some contained no immune antibodies. As some of the sera to be used contained anti-A or anti-B, cells of group $\mathrm{O}$ were used throughout. Errors in ABO grouping must now be very rare and the methods to be described would effectively reveal ABO incompatibility. In order to reproduce as closely as possible the conditions obtaining in hospitals, the blood samples were collected aseptically from bottles taken from the blood-bank of the Regional Transfusion Centre. The blood used was comparable to that issued 
to hospitals, having been withdrawn from the donors from three to 20 days before testing.

In this investigation 72 sera, representing "patients" " sera, were each tested for compatibility with four different cell samples: three were $O R h$ positive and one was $\mathrm{O} \mathrm{Rh}$ negative. A number of the sera were inert; the others were known to contain anti-D. Strongly reacting sera were not chosen, as it was hoped to find a method which would detect anti-D in the low concentrations usually found in patients. The anti-D sera had all been obtained from $\mathrm{Rh}$ negative women immunized by pregnancy, and their specificity and titres had all been confirmed by the M.R.C. Blood Group Reference Laboratory, Lister Institute. The sera were selected by an independent worker from the Sheffield serum panel, and the identity of each serum was not known to the investigator until the experiments were completed.

Altogether, eight different compatibility tests were used, although not every serum was tested against four cells by every method. Of the 72 sera tested, 11 proved to be inert and 61 to contain anti-D. Of these, the Blood Group Reference Laboratory had confirmed that 49 contained incomplete, three complete, and nine a mixture of complete and incomplete anti-D. The inert sera and $\mathrm{Rh}$ negative cells acted as controls.

\section{Methods Used}

Tile Method.-This was included mainly for historical reasons. To one volume of " patient's" serum on an opal glass tile was added one volume of an approximately $5 \%$ suspension of red cells in isotonic saline. The tile was rocked gently and then left to stand at room temperature. Readings were made after 20 minutes.

Tube Method with Saline.-To one volume of " patient's" serum in a precipitin tube was added one volume of a $2 \%$ saline suspension of red cells. The tubes were incubated at $37^{\circ} \mathrm{C}$. for one and a half hours ; the result was read microscopically by removing some of the sedimented cells with a pipette and spreading them gently on to a slide. Before the use of protein media was introduced this was the best available method for detecting immune antibodies.

Tube Method with Saline Followed by Centrifuging.-Serum and cells were mixed as above and incubated for 10 minutes in a $37^{\circ} \mathrm{C}$. incubator. The tubes were then centrifuged for five minutes at approximately 2,000 r.p.m. The sedimented cells were gently agitated by passing two or three air bubbles through them with a Pasteur pipette, and removed and examined as before. Using this technique and reading the results macroscopically, Poole and Williams (1951) found it a reliable method of Rhesus typing-i.e., when unknown cells were being tested with a saline-agglutinating anti-Dbut did not refer to its reliability in direct matching.

Tube Method with Albumin.-Serum and a saline cell suspension were mixed and incubated at $37^{\circ} \mathrm{C}$. for one and a half hours as in the tube method with saline. The supernatant saline was then removed and replaced by an equal volume of $20 \%$ bovine albumin. The tubes were replaced in the incubator for a further 30 minutes. The results were then read microscopically. This technique has been found to give clear-cut and reliable results in $\mathbf{R h}$-typing and is economical in its use of albumin.

Diamond Open-slide Method.-One drop of serum was placed on the slide on top of a Diamond box and five or six drops of whole blood were added. The slide was rocked and readings were made after five minutes. Doubtful reactions, probably due to rouleaux, could usually be read more easily if a drop of saline was added. 
The Diamond test is a useful quick method of $\mathrm{Rh}$ typing when selected, potent antisera are used; Diamond and Abelson (1945) detected anti-Rh agglutinins in nine $\mathbf{R h}$ negative persons (known to have been immunized by transfusion of $\mathrm{Rh}$ positive blood) by this method when the saline tube method gave negative results. It is known, however, that the age of the red cells used greatly affects the sensitivity of this test, and, as Malone (1949) points out, it will fail more often in direct compatibility tests, where one is dealing not only with antibodies of unknown speed of reaction and potency but with stored cells of unknown sensitivity.

Godwin and McCall's Modified Diamond Method.-This method (Godwin and McCall 1949), and the one next described, differ from the Diamond method in that a longer time is allowed for the reaction, drying of the mixture is prevented, and the red cells are suspended in albumin instead of in their own serum.

A $50 \%$ suspension of the prospective donor cells was made in $20 \%$ bovine albumin. Equal volumes of the "patient's" serum and the cell-suspension (two drops of each) were mixed on a slide which was incubated, in a moist chamber, at $37^{\circ} \mathrm{C}$. for 15 minutes. (A petri dish containing a pledget of damp cotton-wool, or some similar device, will serve.) The slide was then removed and the results read by placing over a light and rotating the slide. If agglutination has taken place, the disc of sedimented cells has a serrated edge and on rotating the slide the disc breaks up into clumps, usually easily visible to the naked eye.

"Australian" Modified Diamond Method.-This is a modification of a method for detecting saline agglutinins described in Australia by Krieger and Weiden (1948).

A $5-10 \%$ suspension of "donor" cells in $20 \%$ bovine albumin was prepared. To one volume of the "patient's" serum on a slide one volume of the cell suspension was added and the whole incubated in a moist chamber at $37^{\circ} \mathrm{C}$. for 30 minutes. Agglutinated cells formed an irregularly-edged disc which, when the slide was rotated, broke up into clumps which were in most cases easily visible to the naked eye.

Indirect Coombs Method.-In the hands of trained workers this is undoubtedly the most sensitive method for detecting antibodies. Many antibodies can in fact only be detected by this technique (e.g. anti-Fya and some anti-K). Owing to the scarcity of anti-human globulin, each serum was tested by this method against only one Group $\mathrm{O}$ $\mathrm{Rh}$ positive cell sample. The anti-human globulin was controlled on each day of the investigation, using cells sensitized with a known incomplete anti-D, and unsensitized cells, as positive and negative controls respectively.

\section{Results}

The results are summarized in Table I. A positive result was taken to indicate incompatibility, a negative to indicate compatibility. By comparing the results obtained with the actual antibody-content of the sera used, as was done at the end of the experiment, it was possible to estimate the relative sensitivity of the methods used in detecting the presence of immune antibody. The compatible and incompatible results could then be divided into " true" and "false." The most important figure was that of the "false compatibles," i.e., those where no agglutination took place when known $\mathrm{Rh}$ positive cells were mixed with a " patient's " serum containing anti-D.

In the saline and Diamond tests a number of doubtful reactions were seen, consisting of unevenly distributed clumps of two to three cells in the former, and a faintly granular appearance just visible to the naked eye in the latter. The figures in Table I have been obtained by recording all these doubtful results as positive (incom- 
TABLE I

Results of Direct Compatibility Tests Carried Out by Seven Different Methods

\begin{tabular}{|c|c|c|c|c|c|c|c|c|c|c|c|c|c|}
\hline \multirow{3}{*}{ Method Used } & \multirow{3}{*}{$\begin{array}{l}\text { Total } \\
\text { Tests }\end{array}$} & \multirow{2}{*}{\multicolumn{2}{|c|}{$\begin{array}{c}\text { Total } \\
\text { Incom- } \\
\text { patible } \\
\text { (Positive) }\end{array}$}} & \multirow{2}{*}{\multicolumn{2}{|c|}{$\begin{array}{c}\text { Total } \\
\text { Com- } \\
\text { patible } \\
\text { (Negative) }\end{array}$}} & \multicolumn{4}{|c|}{ Incompatibility } & \multicolumn{4}{|c|}{ Compatibility } \\
\hline & & & & & & \multicolumn{2}{|c|}{ "True" } & \multicolumn{2}{|c|}{ "False" } & \multicolumn{2}{|c|}{$"$ True " } & \multicolumn{2}{|c|}{ "False" } \\
\hline & & No. & $\%$ & No. i & $\%$ & No. & $\%$ & No. 1 & $\%$ & No. & $\%$ & No. & $\%$ \\
\hline $\begin{array}{l}\text { Tile technique } \\
\text { Saline tube } \\
\text { Saline tube with centrifuging } \ldots \\
\text { Albumin tube } . . \\
\text { Original Diamond } \\
\text { Godwin and McCall (modified }\end{array}$ & $\begin{array}{l}256 \\
272 \\
274 \\
274 \\
270\end{array}$ & $\begin{array}{r}44 \\
140 \\
101 \\
173 \\
72\end{array}$ & $\begin{array}{r}1 \cdot 6 \\
51 \cdot 5 \\
36 \cdot 9 \\
63 \cdot 1 \\
26 \cdot 7\end{array}$ & $\begin{array}{l}252 \\
132 \\
173 \\
101 \\
198\end{array}$ & $\begin{array}{l}98 \cdot 4 \\
48 \cdot 5 \\
63 \cdot 1 \\
36 \cdot 9 \\
73 \cdot 3\end{array}$ & $\begin{array}{r}44 \\
135 \\
101 \\
172 \\
70\end{array}$ & $\begin{array}{r}1 \cdot 6 \\
49 \cdot 7 \\
36 \cdot 9 \\
62 \cdot 8 \\
25 \cdot 9\end{array}$ & $\begin{array}{l}0 \\
5 \\
0 \\
1 \\
2\end{array}$ & $\begin{array}{l}0 \cdot 0 \\
1 \cdot 8 \\
0 \cdot 0 \\
0 \cdot 3 \\
0 \cdot 8\end{array}$ & $\begin{array}{r}94 \\
90 \\
102 \\
101 \\
97\end{array}$ & $\begin{array}{l}36 \cdot 6 \\
33 \cdot 1 \\
37 \cdot 2 \\
36 \cdot 9 \\
35 \cdot 9\end{array}$ & $\begin{array}{r}158 \\
42 \\
71 \\
0 \\
101\end{array}$ & $\begin{array}{l}61 \cdot 8 \\
15 \cdot 4 \\
25 \cdot 9 \\
0 \cdot 0 \\
37 \cdot 4\end{array}$ \\
\hline $\begin{array}{l}\text { Diamond) } \\
\text { "Australian " modified }\end{array}$ & 274 & 166 & $60 \cdot 6$ & 108 & $39 \cdot 4$ & 162 & $59 \cdot 1$ & 4 & $1 \cdot 5$ & 98 & $35 \cdot 8$ & 10 & $3 \cdot 6$ \\
\hline Diamond $\quad . . \quad \ldots \quad \ldots$ & 273 & 175 & $64 \cdot 1$ & 98 & 35.9 & 163 & $59 \cdot 7$ & 12 & $4 \cdot 4$ & 88 & $32 \cdot 1$ & 10 & $3 \cdot 8$ \\
\hline
\end{tabular}

patible). In this way the number of "false compatibles" has been reduced to a minimum, and the figures for each method made as far as possible comparable.

Albumin Tube Method.-This gave the most accurate results. No "false negatives" were obtained with this method. In no case did the cells and serum appear to be compatible when they were not so. There was one "false positive": an $\mathrm{Rh}$ positive cell gave a $\mathrm{W}$ reaction with an inert $\mathrm{AB}$ serum. This result could not be repeated and is presumed to be due to technical error. Unagglutinated cells tend to look "sticky" in albumin, but this appearance is quite distinct from the very large clumps easily seen in the positives and there was never any doubt whether a given tube showed a positive or negative result.

Saline Tube Method.-It will be seen from Table I that this method is much less sensitive than the albumin technique because it fails to detect incomplete anti-D in "patient's" sera.

Saline Tube Method with Centrifuging.-This method is rapid, but may possibly give rise to two errors in interpreting the results, due to (1) mistaking groups of sedimented cells for agglutinates; (2) breaking up agglutinates when resuspending the sedimented cells.

This method has shown itself considerably less sensitive than the standard saline tube technique in this investigation, and, like it, fails to detect albumin-agglutinating anti-D.

Tile Technique.-This is included for the sake of completeness. In 256 tests, only four positive results were obtained. Three of these were with an anti-D serum having a titre in saline of 64 , the most powerful serum used in the investigation.

Indirect Coombs Test.-This test is capable of detecting antibodies that cannot be revealed either by saline or albumin techniques. In the present series, however, all the antibodies present were detected by the albumin tube technique. Nearly all the sera were tested by the indirect Coombs test, one sample only of $O R h$ positive cells being sensitized by each serum. The results showed that of 56 anti-D sera 55 gave a positive indirect Coombs test with one negative result, whilst 10 inert sera gave 10 negatives.

The one negative Coombs test with known anti-D serum could not be repeated and was presumably due to technical error. 


\section{Interpretation of Results}

It must be emphasized that the figures obtained refer only to the relative sensitivity of the various methods in detecting a particular type of immune antibody (anti-D). As far as safety in transfusion is concerned, the most important figures are the "false negatives," those tests which gave a result indicating compatibility between patient's serum and "donor's" cells, when, in fact, the serum contained an antibody capable of agglutinating those cells. The percentages of such results for the various methods are given in the right-hand column of Table I. These results show the fallaciousness of compatibility tests in a saline medium, and the reliability of compatibility tests in an albumin medium.

The albumin-tube technique emerges as the most reliable method of detecting weak, incomplete anti-D. It should always be carried out when a direct matching test is requested. Its only disadvantage is that it takes about two hours. The search for a method that will give reliable results in a shorter time has shown that the two modifications of the original Diamond test are superior to the other rapid methods used. Each method detected over $90 \%$ of the antibodies employed. Where $100 \%$ reliability has to be sacrificed to considerations of speed, and when the help of laboratory personnel is not available, one of these methods provides the greatest safety, with the Godwin-McCall giving quicker readings than the "Australian" method. An indirect Coombs test should be performed whenever possible in order to detect those antibodies which can only be demonstrated by that method.

"False Negative" Results in the Modified Diamond Tests. - In view of the high accuracy of these tests an assessment was made of avoidable factors producing occasional "false negatives." Possible causes are (1) low-titre sera, (2) storageperiod of cells, (3) weakly-reacting cells, and (4) errors of technique or interpretation. It appeared that the use of low-titre sera and the length of time the cells had been stored were not related to these "false" results. Three of the cell-samples used gave consistently weaker reactions than other cells by all techniques, and these weakly reacting cells gave "false negatives" in the modified Diamond tests. Finally, three "false negatives" with the "Australian" method were recorded early in the investigation, when little experience of this technique had been gained, and these results may have been due to error of interpretation.

\section{Summary}

The relative sensitivity of eight types of direct compatibility test was estimated by comparing their ability to detect weak immune antibodies (anti-D). The great reliability of tube tests using albumin was demonstrated, as was the insensitivity of similar tests in a saline medium. Of the rapid methods of direct matching, the most reliable were found to be two modifications of the Diamond test. The occasional "false negative" results given by these methods did not show any definite correlation with the age of the cells, or the titre of the sera used. When direct matching which is not urgent is done in hospital laboratories, a tube-test using albumin (and perhaps the indirect Coombs test) should always be carried out. When urgent direct matching has to be carried out and laboratory facilities are not available, the modified Diamond methods described appear to give the most trustworthy results. 
I wish to express my thanks to Dr. R. H. Malone, director of the Blood Transfusion Centre, Sheffield, for permission to publish this paper; and to him and Mr. I. Dunsford, chief technician, for their valuable encouragement, criticism, and advice.

\section{REFERENCES}

Diamond, L. K., and Abelson, N. M. (1945). J. Lab. clin. Med., 30, 204.

Godwin, B., and McCall, A. J. (1949). Brit. med. J., 1, 870.

Krieger, V. I., and Weiden, S. (1948). Amer. J. clin. Path., 18, 572.

Malone, R. H. (1949). Brit. med. J., 1, 1003.

Poole, J. C. F., and Williams, G. C. J.'(1951). Journal of Clinical Pathology, 4, 55. 